\title{
Determinants of Consumer Attitudes and Purchase Intentions With Regard to Genetically Modified Tomatoes
}

\author{
James O. Bukenya \\ Department of Agribusiness, Alabama AAM University, P.O. Box 1042, \\ Normal, AL 35762. E-mail: james.bukenya@email.aamu.edu \\ Natasha R. Wright \\ Department of Agribusiness, Alabama AAM University, P.O. Box 1042, \\ Normal, AL 35762. E-mail: nwright@aamu.edu
}

\begin{abstract}
Although some insights have been gained from previous studies on the acceptability of genetically modified (GM) foods, not many attempts have been made to understand consumer acceptability of genetically modified tomatoes. The purpose of this study is to understand the impact of factors such as consumer knowledge, beliefs, and attitudes on the acceptability of genetically modified tomatoes. The analysis draws on data from a consumer survey conducted at several grocery stores in Alabama in 2003. The results revealed a diversified set of preferences toward GM tomatoes. Logit results suggest that attitude toward the use of genetic modification technology in food production, opinion about labeling, and consumer perceptions about the safety of GM foods strongly influence consumers' decisions. The utility advantage of purchasing non-GM tomatoes corresponds to an average premium of $\$ 0.39$ per pound, implying that consumers would be willing to purchase non-GM tomatoes at a price \$0.39 higher than the price of GM tomatoes. [JEL: O140, Q160, Q180, 110]. (C) 2007 Wiley Periodicals, Inc.
\end{abstract}

\section{INTRODUCTION}

The role of biotechnology in the future of agriculture and food is becoming increasingly significant as billions of dollars are being spent to develop new and improved foods, fuel, feeds, fibers, pharmaceuticals, and nutraceuticals (Hallman, Adelaja, Nayga, Peters, Phillips, \& Thomson, 2002). However, as more products developed through biotechnology reach store shelves, consumer reception for these products has been decidedly mixed. This has especially been the case in Europe (Boccaletti \& Moro, 2000; Burton, Ridby, Young, \& James, 2001) where adoption has been met with caution, and in some cases rejected altogether. In the United States, existing research show that American consumers are relatively uninformed about agricultural biotechnology and have relatively unclear views of genetically modified foods (Hallman et al., 2002; Hoban, 1999; Moon \& Balasubramanian, 2001).

Generally, public debate on the subject is embroiled in the controversy over the risks and benefits of genetically modified products (Barker \& Burnham, 2001; Isserman, 2001; 
Nelson, 2001). Supporters of biotechnology highlight the potential benefits to society via reduction of hunger, cure of diseases, promotion of health, and increased quality of life (Isserman, 2001). Opponents view its use as an unnecessary interference with nature that has unknown and potentially disastrous interactions with human genetics and natural ecosystems (Nelson, 2001). Amidst the controversies, there is a need to understand what consumers want, and want to avoid, with respect to genetically modified (GM) products, as well as consumer characteristics associated with concern for GM foods.

Although some insights have been gained from previous studies, most of the research has focused on the impact of socioeconomic variables and has largely neglected the impact of factors such as consumer knowledge, beliefs, and attitudes. Understanding consumer attitudes and behavior toward GM foods is especially important because of the pace of GMO adoption and because it will soon be difficult, if not impossible, to maintain separate products based on the presence or absence of GMO content (Barboza, 2001). Furthermore, little information is available concerning the relationship between consumer characteristics and the acceptability of genetically modified organism (GMO) products overall, and GM tomatoes in particular. Such information may be useful in guiding the development of food safety policies and regulations, to develop products that address consumer needs, to target informational programs, and to design promotional or advertising campaigns for GM foods.

The remainder of the article is organized into several additional sections. First, in order to understand why consumers in the United States might show a particular attitude towards GMOs overall and GM tomatoes in particular, a brief overview of the main regulatory lines in the United States is presented, followed by a preface of GM tomatoes. Then the analytical framework, which has been used extensively to investigate hypothetical changes in environmental and agricultural polices (Lopez, 1994), and to investigate preferences toward GM foods (Chen \& Chern, 2004; Moon \& Balasubramanian, 2001; Burton et al., 2001 ) is presented. This is followed by the data description, and the econometric approach in which the decision to buy GM versus non-GM tomatoes is specified as a function of attitude, perception, knowledge, and demographic variables. The last sections present the empirical results, implications and conclusions.

\section{GMO REGULATIONS}

The GMO regulatory framework in the United States is based on the Coordinated Framework for Regulation of Biotechnology Products (CFRBP), published in the Federal Register, June 26, 1986. The CFRBP established that biotechnology should be regulated through three existing agencies rather than a new, dedicated agency (Belson, 2000). The three agencies concerned are the Animal and Plant Health Inspection Service (APHIS), the Environmental Protection Agency (EPA), and the Food and Drug Administration (FDA). ${ }^{1}$

${ }^{1}$ USDA's APHIS relied on the Federal Plant Pest Act to deal with GM plants, and now operates under the Federal Plant Protection Act of 2000, which replaced the earlier Act. It has regulations in place relating to the introduction of genetically engineered organisms in the United States. Typically, APHIS is involved in regulating the small-scale field testing of GM plants prior to their commercialization. The EPA is responsible for regulating plants that are genetically engineered to express pesticides such as Bt corn. It operates under three federal statutes: the Federal Insecticide, Fungicide, and Rodenticide Act (FIFR Act), the Federal Food, Drug, and Cosmetic Act (FD\&C Act), and the Toxic Substances and Control Act. The FDA deals with the premarket approval of GMOs and foods containing GM ingredients under the FD\&C Act, and also provides guidelines on the labeling of GM foods (Sheldon \& Josling, 2002). 
The FDA has been at the forefront of articulating the doctrine of substantial equivalence as a basis for regulation of GMOs in the United States.

Essentially, the key to the U.S. approach to regulation of GMOs is the principle of minimal oversight of food products that are generally regarded as safe (GRAS). Conventional food products are considered GRAS, and this is the standard by which GM foods are being judged. The approach recognizes that a zero tolerance for potentially hazardous ingredients in food would result in few foods ever being marketed. In addition, the U.S. regulators recognize that there are practical difficulties in conducting toxicological tests on whole foods as compared to pesticides and food additives. As a result, the concept of GRAS has been adopted as an integral part of the process of evaluating the safety of GM foods (Sheldon \& Josling, 2002).

The objective of such an approach is not to establish absolute safety, but to consider whether a GM food (ingredient) is as safe as its conventional counterpart. The focus is on identifying intended and unintended differences between the two types of food (ingredient), which are then analyzed in a premarket safety assessment (Sheldon \& Josling, 2002). This ideology forms the fundamental difference between the U.S. regulations and those of the European Union and some other countries, including Australia, Brazil, China, Japan, Korea, and New Zealand (Rousu, Huffman, Shogren, \& Tegene, 2004; National Centre for Biotechnology Education [NCBE], 2004). The approach adopted by these countries is based on a precautionary approach to risk assessment and the mandatory labeling of GMOs (Josling \& Patterson, 2001).

The United States currently does not require labeling of GM foods and has not defined a positive tolerance standard. The issue of labeling GM foods was first addressed by the Food and Drug Administration (FDA) in 1992 (Korwek, 2000). In essence, the agency drew on the Federal Food, Drug, and Cosmetic (FD\&C) Act, focusing on sections 403 (a) and 201(n) (Degnan, 2000; FDA, 2001). The first of these requires that food or food ingredients should be described by their common name, and the second requires that labeling of food should detail all facts that are material, ${ }^{2}$ and determines the circumstances under which labeling can be either false or misleading. The agency's 1992 position was that recombinant DNA (rDNA) methods of plant development are not "material" information under the terms of sections 403(a) and 201(n) of the FD\&C Act (Degnan, 2000; Sheldon \& Josling, 2002). Legislation requiring mandatory labeling of GM foods was introduced in the 2000 session of Congress in the House (H.R. 3377) and Senate (S. 2080), but neither bill passed. However, the bills suggested the mix of policy choices being considered by some U.S. legislators (Rousu et al., 2004).

\section{GM TOMATOES}

Although GM tomatoes (Flavr Savr tomatoes) were the first fresh GM fruits or vegetables sold in the world (Soil Association, 2003) most of the GMO debate has focused on GM corn, soybeans, and cotton (Saxena, Flores, \& Stotziky, 1999; William, Price, \& Fernadez-Cornejo, 2001; WWF Report, 2000). However, the focus of the debate has been expanded, following new developments that have brought GM tomatoes back to the forefront. Recently, German and Brazilian researchers have reported genetic modifications to

\footnotetext{
${ }^{2}$ The concept of materiality relates to information about the attributes of food products, and the FDA has typically required labeling of foods with "material" information where that information relates to a health risk, or it substantiates quantitatively any claims made about nutrient content of the food product (FDA, 2001).
} 
tomatoes that will avoid concerns about genetic pollution via cross-pollination (Natural Biotechnology, 2001). The new technique calls for foreign genes to be inserted directly into the chloroplast of the plant cell instead of into the nuclear DNA, which is the most common way to modify a plant genetically. Other plants have been made to express foreign genes, but the tomato is the first to express only in the leaves and the fruit. Scientists hope that this ability to induce foreign protein production will lead to foods with enhanced nutrient or pharmaceutical value (Natural Biotechnology, 2001).

Similarly, researchers at the University of California have developed the world's first GM salt-tolerant tomato plant that can grow in water 50 times saltier than fresh water (Parker, 2001). These new developments have revived the interest in GM tomatoes among researchers, GM companies, farmers, and concerned consumers. The question addressed here is how consumer knowledge and attitude toward GM technology and its application in food production affect the market for GM tomatoes. Our basic premise is that better understanding of consumer beliefs, attitudes, and purchase behavior is essential for GM companies as they make investment decisions and to farmers as they make planting decisions for the second generation of GM tomatoes, which, unlike the first generation, ${ }^{3}$ may offer benefits to the consumer.

\section{CONTINGENT VALUATION METHOD}

Our analytical framework draws on the contingent valuation method-a technique that has been taken up within the environmental valuation literature, where its ability to deal with extended attribute sets (including those related to product and process) give it considerable flexibility (Burton \& Pearse, 2003). The technique is based on eliciting individual willingness to pay (WTP) or willingness to accept (WTA) for a given change in the provision of a good or service "contingent" on a given hypothetical scenario. Specifically, WTP measures the value that consumers place when they purchase goods, whereas WTA measures the value placed when consumers are compensated to lose (or sell) the product. Depending on the wording of the elicitation method, one of the four Hicksian welfare measures is approximated (Hicks, 1941).

The technique has been increasingly used to measure consumers' WTP/WTA for GM foods. Chen and Chern (2004) analyzed an Ohio survey on the consumer acceptance of GM foods and conducted a contingent valuation of WTP for vegetable oil, salmon, and cornflake breakfast cereal. With the use of Norwegian data, Grimsrud, McCluskey, Loureiro, and Wahl (2002) analyzed factors that induce consumers to choose GM food and estimated the willingness to purchase GM bread and GM salmon with discounts. Moon and Balasubramanian (2001) estimated the WTA for breakfast cereals made of non-GM ingredients in the United States and the United Kingdom. Boccaletti and Moro (2000) also attempted to quantify the WTA for generic GM products with different hypothetical attributes in Italy, whereas Burton et al. (2001) calculated the WTA for such products in

\footnotetext{
${ }^{3}$ The first brand of GM tomato (Flavr Savr - a delayed-ripening tomato) first appeared on the U.S. market in 1991 when Calgene, a small biotechnology company in California, genetically modified a tomato that could be picked when ripe and transported without bruising (Soil Association, 2003). Later, Zeneca (now AstraZeneca) modified a tomato to make it bulkier with reduced water content, therefore increasing viscosity and making it more suitable for puree or soup. The company grew the first of these tomatoes in California in 1994. Several other companies (Agritope, Aventis, DNA Plant Technologies, and Seminis) tried to develop GM tomatoes. DNA Plant Technologies test-marketed a tomato called Endless Summer in New York whereas Agritope gained approval to modifying and marketing GM tomatoes from the FDA in 1996 (Soil Association, 2003).
} 
the UK. Recently, Burton and Pearse (2003) have used WTA to identify consumer preferences for various hypothetical forms of genetic modification in beer, using a sample from Western Australia, whereas Bugbee and Loureiro (2003) have contrasted WTP and WTA for GM beef and tomatoes in the western United States. The current analysis contributes to this foundation by eliciting WTP premium for non-GM tomatoes in Alabama.

\section{DATA}

Data used were drawn from a survey questionnaire administered in spring 2003 among food shoppers in one of Alabama's biggest metropolitan areas, Huntsville. A sample of 310 consumers was drawn randomly from people approaching or departing from points of food purchase. ${ }^{4}$ In designing ${ }^{5}$ and administering the questionnaire, special attention was paid to making the hypothetical scenario relevant and credible. Prior to answering the questionnaire, respondents were provided with a brief description of GM technology and its use in food production. Specifically, respondents were provided with the following scenario:

Today, tomatoes are plucked from the vine early, when still green and firm, to ensure that they survive shipping without bruising and rotting. Picking tomatoes early means they have less chance to develop flavor, color, and nutrients naturally. In one of the most recent developments in GM foods, a gene controlling the tomato's ripening process is being manipulated to give the fruit a longer shelf life. By manipulating the rin gene, scientists will be able to slow the ripening process, letting the tomato develop on the vine for a longer period but still keeping it firm and increase shelf life.

Following this description, respondents were asked if they are willing to purchase GM tomatoes if the GM tomatoes were sold at the same price as non-GM tomatoes ${ }^{6}$ (the yes/no responses were the basis for the dependent variable in the logit model). Depending on the response, a follow-up question was asked. Those who answered "yes" to the willingness-to-purchase question (FirstBid) were asked a similar second question, but this time with HighBid > FirstBid. Similarly, respondents who answered "no" to the first willingness-to-purchase question were asked a similar second question with LowBid $<$ FirstBid. ${ }^{7}$ Table 1 shows the price differences based on the range of price discounts offered for GM tomatoes.

The questionnaire also captured personal data including age, gender, ethnicity, income, and educational levels, as well as data about personal beliefs and awareness characteristics: attitude, risk, knowledge, perception, and labeling. A description of these variables

\footnotetext{
${ }^{4}$ The supermarkets were selected in different neighborhoods according to general indicators of economic status.

${ }^{5}$ The design of the survey questionnaire was based on Grimsrud et al. (2002).

${ }^{6}$ The specific wordings of the questions following the brief description of GM foods were as follows: Assume that there is a new GM tomato that can give the fruit a longer shelf life and both GM and non-GM tomatoes of comparable appearance are available at the same price, would you be willing to buy the GM tomatoes? _ Yes _ No

If you responded "no," would you be willing to buy those same GM tomatoes at a price (10-20\%) lower per pound than that of the non-GM tomatoes (regular price $=\$ 2.29 /$ pound)? __ Yes __ No

If you responded "yes," would you be willing to spend (10-20\%) more per pound if the GM tomatoes have longer shelf life than the non-GM tomatoes (regular price $=\$ 2.29 /$ pound)? ___ Yes __ No

${ }^{7}$ The bid discounts were offered at random, ranging from $10-20 \%$ in increments of $2 \%$.
} 
TABLE 1. Price Matrix for CV Design

\begin{tabular}{lcr}
\hline \multicolumn{3}{c}{ Tomato price (\$ per pound) } \\
\hline & \multicolumn{2}{c}{ Price difference } \\
\cline { 2 - 3 } Percentage difference & Non-GM & GM \\
\hline $10 \%$ difference & $\$ 2.29$ & $\$ 2.06$ \\
$12 \%$ difference & 2.29 & 2.02 \\
$14 \%$ difference & 2.29 & 1.97 \\
$16 \%$ difference & 2.29 & 1.92 \\
$18 \%$ difference & 2.29 & 1.88 \\
$20 \%$ difference & 2.29 & 1.83 \\
\hline
\end{tabular}

is given in Table 2. Overall, the data represent consumers who are mostly white, female, less educated and with fairly low income. ${ }^{8}$

\section{ECONOMETRIC APPROACH}

The relationship between consumer characteristics and consumer willingness to purchase non-GM tomatoes at a premium is examined through factors that influence consumers when establishing opinions toward GM technology. Previous studies (Burton et al., 2001; Chen \& Chern, 2004; Hoban, 1999) have documented that consumers' decision-making process is influenced by various factors including their prior knowledge about GM technology, their attitude toward its application in food production, the price difference, and their sociodemographic characteristics. In this case, economic theory emphasizes that the individual will evaluate marginal costs and benefits of making the decision. As marginal benefits are not observed, researchers usually model the difference between benefit and cost through a continuous latent variable. As in the majority of cases, it is not possible to preview how each individual will behave; it is more reliable to estimate a probability that an individual with some attributes will choose a given alternative. To accomplish this, a random utility model by Chen and Chern (2004) was adopted.

Chen and Chern (2004) presented the indirect utility function for respondent $j$ as

$$
U_{i j}=u\left(y_{j}, z_{j}, \varepsilon_{i j}\right)
$$

where $i$ is the dichotomous choice ( 1 as the preferred state and 0 the status quo) and $j$ refers to the respondent. The determinants of utility are $y_{j}$, the $j$ th respondent's income, $Z_{j}$, a vector of respondent characteristics and attributes of the choice, and $\varepsilon_{i j}$, a component of preferences known to the individual respondent but not observed by the researcher.

\footnotetext{
${ }^{8}$ When comparing our sociodemographic figures with Alabama and the United States (U.S. Census Bureau, 2000), the sample has relatively close percentage of females (58\% versus 51.3 and $51 \%$ for Alabama and the United States, respectively); people over 60 years (11.7\% for Alabama and $12.4 \%$ for the United States); and education (high school diploma or less, $35 \%$ and $31.2 \%$ for bachelors degree and above for Alabama). For other figures, it is clear that the sample population has relatively different sociodemographic characteristics than the broader U.S. population; however, it is difficult to assess the effects that may be associated with these differences in our results.
} 
TABLE 2. Variable Definition and Sample Means

\begin{tabular}{llr}
\hline Variable & \multicolumn{1}{c}{$\quad$ Definition and coding } & Mean \\
\hline Gender & $=1$ if female; 0 otherwise & 0.602 \\
Race & $=1$ if White; 0 otherwise & 0.456 \\
Young age & $=1$ if $<40$ years old; 0 otherwise & 0.291 \\
Middle age & $=1$ if 41 to 60 years old; 0 otherwise & 0.373 \\
Focus group & $=>60$ years old & \\
Medium education & $=1$ if some college but no bachelor degree; 0 otherwise & 0.301 \\
High education & $=1$ if 4 years college degree and above; 0 otherwise & 0.322 \\
Focus group & $=$ high school diploma or less & \\
Medium income & $=1$ if income $\$ 30,000$ to $\$ 50,000 ; 0$ otherwise & 0.560 \\
High income & $=1$ if income more than $\$ 50,000 ; 0$ otherwise & 0.208 \\
Focus group & $=$ income less than \$30,000 & \\
Risk & $=1$ if associate GM foods with high risk; 0 otherwise. & 2.678 \\
Focus group & $=$ Do not know & \\
Knowledge & $=1$ if very/somewhat knowledgeable about GM foods; 0 otherwise & 2.230 \\
Perception & $=1$ if feels negative about the safety of GM foods; 0 otherwise & 1.973 \\
Attitude & $=1$ if would consume a dish with GM ingredient; 0 otherwise & 0.671 \\
Shopper & $=1$ if primary shopper; 0 otherwise & 0.846 \\
Labeling & $=1$ if GM foods should be labeled; 0 otherwise & 0.935 \\
Price & $=$ price difference between non-GM and GM tomatoes & 0.344 \\
\hline
\end{tabular}

Accordingly, respondent $j$ chooses the non-GM food if the utility of non-GM food exceeds the utility of the status quo (GM food), given prices:

$$
U_{1 j}\left(Z_{j}, y_{i}-\operatorname{Pngm}_{j}, 1, \varepsilon_{1 j}\right)>U_{0 j}\left(Z_{j}, y_{i}-\operatorname{Pgm}_{j}, 0, \varepsilon_{0 j}\right)
$$

where 1 denotes respondent $j$ choosing the non-GM food, 0 denotes respondent $j$ choosing the status quo (GM food), Pngm $_{j}$ is the price of non-GM food, $P g m_{j}$ is the price of GM food. Therefore, the probability that the respondent thinks he/she is better off by choosing the non-GM food, given its price is expressed as:

$$
\operatorname{Pr} o b\left[\left(U_{1 j}\left(Z_{j}, y_{i}-\operatorname{Pngm}_{j}, 1, \varepsilon_{1 j}\right)>U_{0 j}\left(Z_{j}, y_{i}-\operatorname{Pgm}_{j}, 0, \varepsilon_{0 j}\right)\right]\right.
$$

By assuming a linear form for the utility function, Chen and Chern (2004) specified the utility of respondent $j$ choosing the non-GM food as:

$$
U_{1 j}=\alpha_{1} Z_{j}+\beta_{1}\left(Y_{j}-\text { Pngm }_{j}\right)+\varepsilon_{1 j}
$$

and the utility of respondent $j$ choosing the GM food as:

$$
U_{0 j}=\alpha_{0} Z_{j}+\beta_{0}\left(Y_{j}-P g m_{j}\right)+\varepsilon_{0 j}
$$

If respondent $j$ chooses the non-GM food, it implies that the utility of choosing the non-GM food is greater than that of choosing GM food. By further assuming the marginal utilities of money (income) for non-GM food and GM food to be identical; and the error 
term to have a logistic distribution and to be symmetrical (see Chen \& Chern, 2004 for the full derivation), the probability of choosing the non-GM food is specified as:

$$
\operatorname{Prob}(\text { non-GM })=\left[1+\exp \left(-\left(\alpha Z_{j} / \sigma-\beta \Delta P / \sigma\right)\right)\right]
$$

Following this model, WTP is the proposed price of non-GM tomatoes that would make the respondent indifferent between consuming GM (paid with the current price of the GM tomatoes) and the non-GM tomatoes. Thus, the WTP for the non-GM tomatoes is defined as (Chen \& Chern, 2004):

$$
\alpha_{1} Z_{j}+\beta\left(y_{j}-\text { WTPngm }_{j}\right)+\varepsilon_{1 j}=\alpha_{0} Z_{j}+\beta\left(y_{j}-\text { WTPgm }_{j}\right)+\varepsilon_{0 j}
$$

Solving Equation 7 for WTP yields:

$$
\text { WTPngm }_{j}-\text { WTPgm }_{j}=\alpha Z_{j} / \beta+\varepsilon_{j} / \beta
$$

where $\alpha=\alpha_{1}-\alpha_{0}$ and $\varepsilon_{j}=\varepsilon_{1 j}-\varepsilon_{0 j}$. As noted by Chen and Chern (2004), a consistent estimate of expected willingness to pay for a non-GM food product derived from Equation 8 is:

$$
E\left(W_{T P n g m}-W T P g m_{j} \mid \alpha, \beta, Z_{j}\right)=\alpha Z_{j} / \beta
$$

where $\alpha$ is a vector of the estimated coefficients of the explanatory variables and $\beta$ is the estimated coefficient of the price difference between non-GM and GM tomatoes (Chen \& Chern, 2004). By adopting the logistic model to estimate the probability of choosing the non-GM tomatoes, the econometric model is specified as the logit model:

$$
y=\alpha k+\beta p+\varepsilon
$$

where $y= \begin{cases}1 & \text { if the respondent chooses to buy the non-GM tomatoes } \\ 0 & \text { otherwise. }\end{cases}$

Also, $k$ is a vector of explanatory variables and $p$ is price factor. The price factor in the current empirical model is defined as the price difference between non-GM and GM tomatoes in order to capture the price effect and WTP is estimated as the expected premium for non-GM tomatoes.

\section{ESTIMATED RESULTS}

The results are presented in Table 3, including the log-likelihood coefficient, the Nagelkerke $R^{2}$, the model's prediction success, the estimated WTP premium, and the percentage of premium. The measures of goodness of fit indicate the model fits the data fairly well. The log-likelihood, which measures the significance of logit function, was significant at $p<.01$, suggesting a relationship exists between the probability of a respondent choosing non-GM tomatoes and the suggested independent variables. Although the $R^{2}$ value is low, which is the norm in logistic regression (Hosmer \& Lemeshow, 2000); the model correctly predicted $77 \%$ (225 out of 292) of the responses. 
TABLE 3. Estimated Logit Regression Results

\begin{tabular}{|c|c|c|c|c|}
\hline \multirow{2}{*}{$\frac{\text { Logit model }}{\text { Variable }}$} & \multicolumn{4}{|c|}{$\begin{array}{c}\text { Dependent variable }= \\
\text { Assessment of willingness to purchase non-GM tomatoes }\end{array}$} \\
\hline & Coefficient & $S E$ & $P$ value & $\Delta$ probability \\
\hline Constant & $0.872 * * *$ & 0.337 & 0.010 & - \\
\hline Race & 0.217 & 0.347 & 0.532 & 0.041 \\
\hline Female & 0.392 & 0.304 & 0.198 & 0.067 \\
\hline Young age & -1.259 & 1.199 & 0.294 & -0.303 \\
\hline Middle age & 0.082 & 0.385 & 0.831 & 0.016 \\
\hline Medium education & -0.325 & 0.418 & 0.437 & -0.075 \\
\hline High education & 0.468 & 0.437 & 0.284 & 0.077 \\
\hline Medium income & -0.680 & 0.482 & 0.158 & -0.168 \\
\hline High income & $1.042 * * *$ & 0.430 & 0.015 & 0.117 \\
\hline Primary shopper & $-2.443 * * *$ & 0.937 & 0.009 & -0.348 \\
\hline Knowledge & -0.255 & 0.358 & 0.477 & -0.058 \\
\hline Attitude & $-0.749 * * *$ & 0.253 & 0.003 & -0.103 \\
\hline Risk & $0.385 * * *$ & 0.146 & 0.009 & 0.066 \\
\hline Label & $0.462 * *$ & 0.229 & 0.044 & 0.076 \\
\hline Perception & $1.066 * * *$ & 0.444 & 0.016 & 0.117 \\
\hline Price & $-0.556^{*}$ & 0.319 & 0.081 & -0.136 \\
\hline Log likelihood & -135.470 & & & \\
\hline Nagelkerke $R^{2}$ & 0.065 & & & \\
\hline Sample size & 292 & & & \\
\hline Model prediction & $77 \%$ & & & \\
\hline WTP premium & $\$ 0.390 /$ pound & & & \\
\hline Percent of premium & $19-21 \%$ & & & \\
\hline
\end{tabular}

* Significant at the $10 \%$ level of probability.

**Significant at the $5 \%$ level of probability.

$* * *$ Significant at the $1 \%$ level of probability.

In the case of the explanatory variables, the estimated results are interpreted with the use of the change in probability $\left(\Delta P_{i}\right)$ as:

$$
\Delta P_{i}=\alpha_{k} P_{i}\left(1-P_{i}\right)
$$

where $P_{i}$ is the estimated probability of choosing non-GM tomatoes evaluated at the mean, and $\alpha_{k}$ is the estimated coefficient of the $k$ th variable. The change in probability $\left(\Delta P_{i}\right)$ is a function of the probability, and when multiplied by 100 gives the percentage change in the probability of the event occurring given a change in the variable, all things being equal.

As shown by the results in Table 3, sociodemographic characteristics turn out to be insignificant with respect to age, race (indicating white), gender (indicating female), education, and median income (indicating $\$ 30,000$ to $\$ 50,000$ ). The only sociodemographic characteristics found to be significant determinants of whether or not a consumer in the sample would purchase non-GM tomatoes at a premium are high income (indicating income above $\$ 50,000$ ) and primary shopper (indicating primary food shopper in the household). 
With regard to high income, the estimated coefficient is positive, implying that consumers with incomes above $\$ 50,000$ were more likely to purchase non-GM tomatoes at a price higher than the price of GM tomatoes. The change in probability estimates (last column in Table 3) suggests consumers with incomes above $\$ 50,000$ were $11.7 \%$ more likely to pay a premium to avoid GM tomatoes than consumers with incomes less than $\$ 30,000$. In the case of primary shoppers, the estimated coefficient is negative, implying that respondents who are primary food shoppers in the household are less likely to purchase non-GM tomatoes at a price higher than the price of GM tomatoes. The change in probability suggests primary shoppers were $34.8 \%$ less likely to pay a premium to avoid GM tomatoes.

Looking at personal beliefs and awareness characteristics, the results suggest that attitude toward the use of GM technology in food production and perceptions about the safety of GM foods are significant determinants of whether or not a consumer in the sample would purchase non-GM tomatoes at a price higher than that of GM tomatoes. The estimated coefficient for attitude has a negative sign, implying that consumers who had a positive attitude toward the use of GM technology in food production were less likely to purchase non-GM tomatoes at a higher price. The estimated change in probability suggests that consumers with a positive attitude toward food products with GM ingredients were $10.3 \%$ less likely to pay a premium to avoid GM tomatoes. Similarly, the estimated coefficient for perception has a positive sign, meaning that consumers concerned with the safety of GM foods are more likely to purchase non-GM foods at a higher price than that of GM foods. The change in probability with regard to perceptions indicates consumers who feel negative about the safety of GM foods were $11.7 \%$ more likely to pay a premium to avoid GM tomatoes.

The variables measuring consumer opinion about labeling GM foods and the risk levels associated with GM foods are also shown to have positive effects on whether or not a consumer in the sample would be willing to purchase non-GM tomatoes at a premium. The results imply, for instance, that the more important labeling of GM foods is to the respondents, the more likely they are to purchase non-GM foods. Likewise, the higher the risk consumers associate with GM foods, the more they are likely to purchase non-GM foods. The change in probability estimates suggests that labeling GM tomatoes would result in approximately $7.6 \%$ increase in the probability of consumers paying a premium to avoid GM tomatoes, and the change in probability with regard to risk levels indicates consumers associating GM foods with high risk were $6.6 \%$ more likely to pay a premium to avoid GM tomatoes.

The variable measuring self-reported GM knowledge has a negative sign; implying that knowledge about GM technology encourages consumers to purchase more GM foods. However, the coefficient is insignificant, suggesting that knowledge about GM technology is not a significant factor in guiding consumers' purchasing decision. In the case of price difference, the negative and statistically significant coefficient suggests that lower prices of GM foods encourage consumers to consume more GM food products. The negative coefficient was consistent with the Chen and Chern (2004) earlier study. For each incremental increase in price, there was a decrease of approximately $1.4 \%$ in the probability of willingness to pay a premium to avoid GM tomatoes.

\subsection{Willingness to Pay for Non-GM Tomatoes}

The reported willingness to pay (WTP) estimates for non-GM tomatoes reflects the mean premium (computed for the entire sample) that consumers are willing to pay to avoid GM 
TABLE 4. Estimated WTP Premium for Non-GM Tomatoes by Demographic Groups

\begin{tabular}{lcc}
\hline Variable & WTP premium & Parentage of premium \\
\hline Sex & & \\
$\quad$ Female & $\$ 0.183$ & $8.9-10 \%$ \\
$\quad$ Male & $\$ 0.215$ & $10-11.7 \%$ \\
Age & & \\
$\quad<40$ years old & $-\$ 0.306$ & $(-14)-(-16) \%$ \\
$41-60$ years old & $\$ 0.048$ & $2-3 \%$ \\
$>60$ years old & $\$ 0.034$ & $2-3 \%$ \\
Race & & \\
$\quad$ White & $\$ 0.097$ & $4.7-5.3 \%$ \\
$\quad$ Non-White & $\$ 0.115$ & $5.6-6.3 \%$ \\
\hline
\end{tabular}

tomatoes. The results suggest that on average, respondents would be willing to pay a premium of $\$ 0.39$ per pound for non-GM tomatoes (Table 3). The percentage of the premium is also computed based on the different prices (Table 2) of the GM tomatoes. The results show that respondents are willing to pay a percentage premium of $19-21 \%$ for non-GM tomatoes.

Even though demographic variables are not statistically significant in the logit model, the computed WTP premiums can still be different among demographic groups, because WTP is based on the entire set of estimated parameters (Chen \& Chern, 2004). Thus, we computed the WTP premium for various demographic groups by sex, age, and race. According to the results presented in Table 4, the estimated WTP premiums ${ }^{9}$ are positive for all categories except for respondents who are less than 40 years old. For this category, the estimated WTP premium is $-\$ 0.306$, implying that young-age respondents are willing to pay a premium of $\$ 0.306$ for GM tomatoes. To the contrary, the WTP premiums for respondents $41-60$ years old and those above 60 years are estimated at $\$ 0.048$ and $\$ 0.034$, respectively. These results suggest that middle-aged and old respondents are willing to pay a premium of $\$ 0.048$ and $\$ 0.034$, respectively, to avoid GM tomatoes. As for sex, the estimated WTP premiums are $\$ 0.183$ and $\$ 0.215$ for female and male respondents, respectively; whereas the estimated WTP premiums to avoid GM tomatoes for race are $\$ 0.097$ for White and \$0.115 for non-White respondents.

\section{IMPLICATIONS}

The results show that consumer perception of whether or not GM foods are safe is a significant factor in determining consumers' willingness to pay a premium to avoid GM foods, in general and GM tomatoes, in particular. This finding provides policy makers with an opportunity to design a credible regulatory process for assuring consumers that GM products reaching the market are safe. Such a process might involve process documentation, environmental testing, or labeling prior to a product's approval (Barker \& Burnham, 2001). A stringent regulatory process and the government's stamp of approval

\footnotetext{
${ }^{9}$ Following a suggestion by one of the reviewers, the WTP premiums for the various demographic groups are computed by using the estimated parameters for each respondent in the sample and then the mean WTP values for each demographic group were derived.
} 
may make GM foods overall, and GM tomatoes in particular, more acceptable to riskaverse consumers.

Similarly, education about GM technology and its use in food production is often proposed as the remedy for consumers who make "uninformed" decisions (Barker \& Burnham, 2001). The results on the influence of the GM knowledge variable on consumer acceptance of GM tomatoes in particular and GM foods overall, supports this recommendation. However the coefficient for the knowledge variable was not statistically significant, and the magnitude of this variable's influence was roughly one-fifth of those of GM attitude and perception variables. This suggests, as noted by Barker and Burnham (2001), that consumer behavior is determined less by how much consumers know, and more by what they believe.

Furthermore, the opportunity to gain consumer confidence by way of strong regulations may be a unique opportunity for U.S. policy makers, because of the country's strong regulatory institutions and the high level of public confidence in institutions such as the FDA, the EPA, and the USDA. In contrast, such an approach would likely face a much greater challenge in Europe, where regulatory institutions suffer from a low level of public confidence (Sheldon \& Josling, 2002). As noted by Sheldon and Josling (2002), acceptance increases significantly in the United States when American consumers learn that organizations such as the National Academy of Sciences and the FDA have determined that biotech-derived foods are safe-they have much less confidence in those groups that oppose biotechnology. In contrast, European consumers express the most trust in those groups that oppose biotechnology - they have much less confidence in government, industry, or even scientists.

\section{CONCLUSIONS}

A consumer survey was conducted at several grocery stores in Alabama in 2003 to investigate consumer willingness to purchase GM tomatoes. Logit model results indicated that attitude toward GM technology and its use in food production, opinion about labeling GM foods, and concern about the safety of GM foods, are significant determinants of whether or not a consumer in the sample would purchase non-GM tomatoes at a premium. The effect of price was also reflected by the significance of the price difference variable, indicating that more GM tomatoes would be purchased if the price difference between GM and non-GM tomatoes increases. Generally, sociodemographic variables were not significant factors. Only high income and being a primary shopper in the household affect consumers' purchase decisions. Estimated mean WTP results indicated that the utility advantage of non-GM tomatoes corresponds to an average premium of $\$ 0.39$ per pound; implying that on average, consumers in the sample would be willing to pay a premium of $\$ 0.39$ to avoid GM tomatoes.

\section{REFERENCES}

Barker, A.G., \& Burnham, T.A. (2001). Consumer response to genetically modified foods: Market segment analysis and implications for producers and policy makers. Journal of Agricultural and Resource Economics, 26, 2, 387-403.

Barboza, D. (2001, June 10). As biotech crops multiply, consumers get little choice. New York Times, pp. 1, 28.

Belson, N.A. (2000). US regulation of agricultural technology: An overview. AgBioForum, 3/4, 268-280. 
Boccaletti, S., \& Moro, D. (2000). Consumer willingness to pay for GM food products in Italy. AgBioForum, 3, No. 4/Article 14. Available: http://www.agbioforum.org/v3n4/v3n4a14boccaletti.htm.

Bugbee, M.J., \& Loureiro, M.L. (2003). A risk perception analysis of genetically modified foods based on stated preferences. Paper presented at the American Agricultural Economics Association Annual Meeting, Montreal, Canada.

Burton, M., \& Pearse, D. (2003). Consumer attitudes towards genetic modification, functional foods, and microorganisms: A choice modeling experiment for beer. AgBioForum, 5, 51-58.

Burton, M., Rigby, D., Young, T., \& James, S. (2001). Consumer attitudes to genetically modified organisms in food in the UK. European Review of Agricultural Economics, 28, 479-498.

Chen, H., \& Chern, W.S. (2004). Willingness to pay for GM foods: Results from a public survey in the U.S. In R.E. Evenson \& V. Santaniello (Eds.), Consumer acceptance of genetically modified foods. Oxon, UK: CABI Publishing.

Degnan, F.D. (2000). Biotechnology and the food label: A legal perspective. Food \& Drug Law Journal, 55, 301-302. Available: http://www.fdli.org/pubs/Journal\%20Online/55_3/ art2.pdf

Food and Drug Administration. (2001, January). Voluntary labeling indicating whether foods have or have not been developed using bioengineering. Draft guidance. Washington, DC: U.S. Department of Health and Human Services, FDA.

Grimsrud, K.M., McCluskey, J.J., Loureiro, M.L., \& Wahl, T.I. (2002). Consumer attitudes toward genetically modified food in Norway. American Agricultural Economics Association's Annual Meeting, July 28-31, Long Beach, California.

Hallman, W., Adelaja, A., Nayga, R., Peters, H., Phillips, P., \& Thomson, J. (2002). Consumer acceptance of food biotechnology in the United States. Food Policy Institute, Rutgers University, New Brunswick.

Hicks, J.R. (1941). The rehabilitation of consumers' surplus. Review of Economic Studies, 8, 108-116.

Hoban, T.J. (1999). Public perceptions and understanding of agricultural biotechnology. Available: www.usia.gov/journals/ites/1099/ijee/bio-toc.htm

Hosmer, D.W., \& Lemeshow, S. (2000). Applied logistic regression (2nd ed.). New York: John Wiley \& Sons.

Isserman, A.M. (2001). Genetically modified food: Understanding the social dilemma. American Behavioral Scientist, 4(8), 1225-1232.

Josling, T., \& Patterson, L.A. (2001). Biotechnology regulatory policy in the United States and the European Union: Source of transatlantic trade conflict or opportunity for cooperation." Paper presented at the 76th annual conference of the Western Economic Association International, San Francisco, CA, July 4-8.

Korwek, E.L. (2000). Labeling biotech foods: Opening Pandora's box? Food Technology, 54, $38-42$.

Lopez, R. (1994). The environment as a factor of production: The effect of economic growth and trade liberalization. Journal of Environmental Economics and Management, 27, 163-184.

Moon, W., \& Balasubramanian, S.K. (2001). Estimating willingness to pay for nonbiotech foods: A comparison across US and UK consumers. AgBioForum: Journal of Agrobiotechnology Management and Economics, 4(3/4): Article 10.

Natural Biotechnology. (2001). Environmentally friendly GM tomatoes. Natural Biotechnology, 870-875. Available: ttp://www.nature.com/nbt/press_release/nbt0901.html

NCBE. (2004). Genetically modified foods. Available: http://www.ncbe.rdg.ac.uk/NCBE/ GMFOOD/menu.html.

Nelson, C.H. (2001). Risk perception, behavior and consumer response to genetically modified organisms. American Behavioral Scientist, 44(8), 1371-1388.

Parker, C. (2001). Salt tolerant GM tomatoes. Available: http://www.abc.net.au/rural/nt/stories/ s341634.htm

Rousu, M., Huffman, W.E., Shogren, J.F., \& Tegene, A. (2004). Are United States consumers tolerant to genetically modified foods? Review of Agricultural Economics, 26, 19-31.

Saxena, D., Flores, S., \& Stotzky, G. (1999). Transgenic plants: Insecticidal toxine in root exudates from Bt corn. Nature, 402, 480.

Sheldon, I., \& Josling, T. (2002). Biotechnology regulations and the WTO. Working Paper 02-2. Available: http://www.iatrcweb.org. 
Soil Association. (2003). Flavr Savr tomato and GM tomato puree: The failure of the first GM foods. A briefing paper. Available: http://www.soilassociation.org/web/sa/saweb.nsf/ librarytitles/Briefing_Sheets07052003.html

William, L., Price, G.K., \& Fernadez-Cornejo, J. (2001). Estimating farm-level effects of adopting of herbicide-tolerant soybeans. Economic Research Service, USDA Available: http://www. ers.usda.gov/briefing/biotechnology/readings.htm

WWF Report. (2000). Transgenic cotton: Are there benefits for conservation? A case study on GMOs in agriculture, with special emphasis on fresh water. WWF Background Paper, March 2000. Available: http://www.panda.org/livingwaters

James O. Bukenya is a research assistant professor in the Department of Agribusiness at Alabama AAM University. He obtained his Masters degree in Agribusiness in 1999 and his doctorate degree in Natural Resource Economics in 2001. His research interests are in rural development, regional economics, and related issues in labor markets, human capital, and demographic change. Secondary interests are in production economics, resource management, spatial analysis, and geographical information systems.

Natasha R. Wright is a former graduate research assistant in the Department of Agribusiness at Alabama AAM University. She received her Masters degree in 2003. Her research interests are in commodity markets and food distribution. 